\title{
Pursuing two-dimensional nanomaterials for flexible lithium-ion batteries
}

\author{
Bin Liu, ${ }^{\mathrm{a}, \mathrm{b}} \mathrm{Ji}-$ Guang Zhang, ${ }^{\mathrm{a}}$ Guozhen Shen*b
}

a. Energy and Environment Directorate, Pacific Northwest National Laboratory, Richland, Washington 99354, United States

b. State Key Laboratory for Superlattices and Microstructures, Institute of Semiconductors, Chinese Academy of Sciences, Beijing 100083, P. R. China

Corresponding Author

*E-mail: jiguang.zhang@pnnl.gov; gzshen@semi.ac.cn 
Summary Stretchable/flexible electronics provide a foundation for various emerging applications that beyond the scope of conventional wafer/circuit board technologies due to their unique features that can satisfy a broad range of applications such as wearable devices. Stretchable electronic and optoelectronics devices require the bendable/wearable rechargeable Li-ion batteries, thus these devices can operate without limitation of external powers. Various two-dimensional (2D) nanomaterials are of great interest in flexible energy storage devices, especially Li-ion batteries. This is because 2D materials exhibit much more exposed surface area supplying abundant Li-insertion channels and shortened paths for fast lithium ion diffusion. Here, we will review the recent developments on the flexible Li-ion batteries based on two dimensional nanomaterials. These researches demonstrated advancements in flexible electronics by incorporating various 2D nanomaterials into bendable batteries to achieve high electrochemical performance, excellent mechanical flexibility as well as electrical stability under stretching/bending conditions.

\section{Keywords}

Two-dimensional; flexible batteries; nanomaterials; potential application 


\section{Introduction}

Increasing demands for high-efficiency, environmentally friendly and low-cost energy sources are associated with the increase concern on energy independence and environment concerns [19]. Among various energy storage systems, rechargeable lithium-ion batteries are one of the most promising power sources to alleviate energy crisis [10-15]. Although significant progresses have been made on Li-ion batteries (LIBs) in the last a few decades, most of these batteries are still short of features of such as flexibility, bendability, wear-ability, which forms a barrier for the development of next-generation flexible optoelectronic products [16-24]. The increasing interest in flexible and stretchable electronics has promoted the rapid development of flexible batteries. Here, all these components (including cathode, anode, electrolyte, separator, and packing material) in a flexible battery need to be flexible and bendable. The paramount goal of on-going research on flexible batteries is to smoothly maintain the expected battery stability under various bending states. Moreover, different curving and stretching level of flexible rechargeable batteries would be designed and fabricated, depending on their various application fields, while the traditional batteries are rigid with certain shapes. Thus, significant efforts are being made around world to fabricate highly flexible rechargeable batteries [25-35].

To overcome the tremendous challenge of fabrication of highly stable flexible Li-ion batteries, utilizing nano-structure materials to prepare electrodes is one of the most promising strategies. It is well-known that nanomaterials can be classified in four categories: zero dimensional (0D), one dimensional (1D), two dimensional (2D), and three dimensional (3D). Here, 0D structures (nano/microsphere) hold the minimum surface area, and exhibit excellent thermal stability. 1D structures (nanotubes/nanowires) fabricated by oriented growth have a potential application for micro-devices. 2D structures (nanosheets) often have large exposed surfaces, and specific facets. 
In general, 3D structures could be obtained by introducing structure directing agents (SDAs) or assembled by $0 \mathrm{D}, 1 \mathrm{D}$, and $2 \mathrm{D}$ structures [36]. In particular, comparing to $0 \mathrm{D}$, and $1 \mathrm{D}$ nanomaterials, 2D nanomaterials exhibit many unique features, such as small weight, large surface area, sensible distribution, more active sites with effective surface. Therefore, it would be highly desirable to use 2D nanomaterials in the design and preparation of flexible energy storage devices.

In this review, we will focus on advances on typical two-dimensional (2D) functional materials for flexible/bendable lithium-ion batteries, such as flexible 2D graphene paper, various graphene-based composite cathodes and anodes, 2D inorganic nanosheets, etc, as shown in Fig. 1. How to better understand the selection, design, and optimization of these aforementioned bendable and free-standing electrodes should be a key sweet spot for next-generation flexible LIBs chemistries. It is expected that this overview will not only summarize the highlighted developments of 2D nanomaterials-based flexible energy storage field but also shine light on the directions for further development of 2D functional nanomaterials for various applications.

\section{Flexible two dimensional graphene-based electrodes for $\mathrm{Li}$-ion batteries}

Recently, more and more interests were focused on portable and bendable electronic units such as roll-up displays, wearable devices, and implanted medical devices [37,38]. However, the design and fabrication of bendable batteries is facing a significant challenge: how to find reliable flexible materials with robust strength, good conductivity, and excellent electrical stability under bending. Among two-dimensional materials, graphene is an atom-thick two-dimensional carbon sheet. The $\sigma$ carbon-carbon bond is the strongest single bond in nature, resulting in graphene with high Young's modulus and tensile strength [39]. Therefore, graphene as active material was 
also smoothly introduced into high performance flexible energy storage devices due to their potential superiority in terms of mechanical flexibility and charge-carrier mobility [40].

\subsection{Flexible two-dimensional graphene paper}

Graphene paper has dual functions and can act both as a conducting agent and a current collector. Clearly, based on graphene's features, the graphene paper itself holds some unique properties, making it a key factor for development of flexible LIBs [41-44]. Fabrication of graphene papers have been reported previously [41,43-45]. Briefly, it is well-known that graphite oxide can be synthesized from graphite powder by oxidation using a typical Hummers method [46]. Then, graphene paper was usually fabricated by filtration of graphene dispersions $[41,43-45,47]$. Koratkar et al. introduced photothermal reduction of graphene oxide to obtain graphene paper anodes, the corresponding procedures and characterizations are shown in Fig. 2a-2d [44]. Clearly, a free-standing graphene paper exhibits good bendable features (Fig. 2c) so it is a good candidate to be used in flexible-batteries. In Fig. 2e, these flexible graphene paper electrodes showed excellent cycling stability over 1000 discharge/charge times and high rate capability (20 C, 40 C, 100 C, and 150 C). Clearly, extensive developments of graphene papers will trigger more research on flexible optoelectronics in the near future. Liu et al. fabricated the flexible graphene paper made from the graphene aerogel pre-synthesized by freeze-drying a GO aqueous dispersion and subsequent thermal reduction [48]. The free-standing graphene paper shows excellent flexibility as shown in Fig. 3a-3c. The well-packed layers can be observed in the whole paper sample (Fig. 3d). The fracture edge of a graphene paper sample is revealed in the inset of Figure 1d, which demonstrates well stacked graphene sheets. In addition, flexible graphene paper indicates enhanced cyclic stability (over 100 times), and good rate capability (Fig. 3e and 3f), 
thus providing a possibility to act as a new kind of flexible electrode for wearable/rolling-up optoelectronics devices.

\subsection{Flexible two-dimensional graphene composite paper anodes}

Considering 2D graphene sheets with a large surface, these graphene sheets can serve as a building template to compose other active materials to form various flexible functional electrodes. Lots of flexible graphene/active material composite anodes, such as flexible graphene/ $\mathrm{TiO}_{2}$ nanoparticles composite paper [49,50], graphene/ $\mathrm{Co}_{3} \mathrm{O}_{4}$ fibers composite paper [51], graphene/ $\mathrm{SnO}_{2}$ nanoparticles paper [52], graphene/ $\mathrm{MnO}_{2}$ nanotube hybrid film [53], have been developed. Most functional materials were deposited onto pre-obtained graphene paper via hydrothermal, filtration, immersion followed by thermal decomposition methods [50-54]. For example, $\mathrm{Hu}$ et al. reported an ex-situ method to prepare a flexible graphene/ $\mathrm{TiO} \mathrm{O}_{2}$ nanoparticles hybrid paper electrode [49]. Because of the highly conductive graphene network, the flexible composite paper electrode reaches a capacity of $122 \mathrm{~mA} \mathrm{~h} \mathrm{~g}^{-1}$ at $2 \mathrm{~A} \mathrm{~g}^{-1}$ after 100 cycles. Surface structure is considered as a key factor to determine the rate of the $\mathrm{Li}^{+}$ion deintercalation/intercalation process. Yang et al. fabricated $\mathrm{Co}_{3} \mathrm{O}_{4}$ fibers using electrospinning technique, then got graphene $/ \mathrm{Co}_{3} \mathrm{O}_{4}$ fibers composite papers by depositing graphene nanosheets on $\mathrm{Co}_{3} \mathrm{O}_{4}$ active materials via electrostatic interaction, indicating a large reversible capacity (840 $\mathrm{mAh} \mathrm{g}^{-1}$ after 40 cycles), and improved cycling stability [51]. Liang et al. prepared flexible freestanding graphene/ $\mathrm{SnO}_{2}$ nanocomposite papers by a facile filtration route together with a thermal reduction [52]. To utilize unique respective advantages of $\mathrm{SnO}_{2}$ and graphene, the $\mathrm{SnO}_{2}$ nanoparticles are embedded into layers of $2 \mathrm{D}$ graphene sheets, two layers including $\mathrm{SnO}_{2}$ nanoparticles and graphene sheets are distributed uniformly, as shown in different magnification FESEM cross-section and top-view images (Fig. 4a-4e). An as-synthesized free-standing 
$\mathrm{SnO}_{2} /$ graphene film can be bent by a tweezer, thus indicating its excellent flexibility (Fig. 4f). Although graphene/ $\mathrm{SnO}_{2}$ composite electrodes exhibited a low capacity during the first few cycles due to poor electrolyte wetting of the dense graphene/ $\mathrm{SnO}_{2}$ paper, their corresponding discharge capacity still reach $428 \mathrm{mAh} \mathrm{g}^{-1}$ after 50 cycles (about $83.4 \%$ retention those at $25^{\text {th }}$ cycle), as illustrated in Fig. 4g. In contrary, bare $\mathrm{SnO}_{2}$ electrodes delivered poor cycling stability. Fig. 4h shows that the graphene/ $\mathrm{SnO}_{2}$ electrode in the high-medium frequency region exhibits a much smaller charge transfer resistance than that of the $\mathrm{SnO}_{2}$ electrode (as revealed by a much smaller diameter of the semicircle in the impedance spectra of the graphene/ $\mathrm{SnO}_{2}$ electrode). Huang et al. loaded the transition-metal oxides $\left(\mathrm{Fe}_{3} \mathrm{O}_{4}, \mathrm{Co}_{3} \mathrm{O}_{4}\right.$, and $\left.\mathrm{NiO}\right)$ into the nanoporous graphene papers via a general wet-immersion route to form free-standing flexible composite papers. These flexible composite electrodes exhibited enhanced electrochemical performance [54].

Beside above binary inorganic materials, because silicon has very high theoretical capacity (4200 mAh g ${ }^{-1}$ ), it has been combined with graphene with unique features to synthesize bendable free-standing hybrid anodes for flexible Li-ion batteries [55-57]. For example, Wang et al. proposed fabrication of flexible and paper-like graphene-silicon composites by a one-step in-situ filtration method [58]. The flexible graphene-Si composite electrodes showed much higher discharge capacity over 100 cycles (708 $\mathrm{mAh} \mathrm{g}^{-1}$ ) than that of the graphene electrodes (304 mAh $\left.\mathrm{g}^{-1}\right)$. Here, 2D graphene can serve as a flexible mechanical and efficient electrically conducting support. In addition to flexible two-component (graphene-Si) electrode, flexible binder-free SiNW@G@RGO hybrid materials were also designed [56]. Firstly, SiNW@G nanocables were grown via chemical vapor deposition (CVD) approach. Then, SiNW@G nanocables were dispersed in GO solution. The homogeneous mixture was vacuum filtered, peeled from the filter 
membrane. Finally, flexible SiNW@G@RGO composite anodes were obtained after thermal treatment. The morphologies of as-fabricated SiNW@G@RGO can be found in Fig. 5a-5d. In addition, compared to two other electrodes based on SiNW@G and SiNW, flexible SiNW@G@RGO electrodes exhibit higher reversible specific capacity of over 1500 mAh g ${ }^{-1}$ at $840 \mathrm{~mA} \mathrm{~g}^{-1}$ (Fig. 5e), and even reach $1600 \mathrm{mAh} \mathrm{g}^{-1}$ at $2.1 \mathrm{~A} \mathrm{~g}^{-1}$ with $80 \%$ capacity retention after 100 cycles (Fig. 5f).

\subsection{Flexible two-dimensional graphene composite cathodes}

In addition to composite anodes, various cathode materials were also incorporated into 2D graphene films by using catalyst assisted self-assembly, co-precipitation, pulsed laser deposition (PLD), microwave hydrothermal, and photothermal reduction methods [59,60,62-64]. These composite cathodes include graphene/ $\mathrm{LiFePO}_{4}$ nanoparticles [59-61], graphene/ $\mathrm{V}_{2} \mathrm{O}_{5}$ films [62], graphene/ $\mathrm{MoO}_{3}$ nanobelts [63], and graphene/ $\mathrm{FeF}_{3}$ nanoparticles [64]. Li et al. proposed a new design of flexible batteries based on $\mathrm{Li}_{4} \mathrm{Ti}_{5} \mathrm{O}_{12}$ (LTO)/graphene form (GF) and $\mathrm{LiFePO}_{4}$ (LFP)/GF electrodes by hydrothermal deposition of active materials on GF followed by heating in an argon atmosphere [61]. Fig. 6a shows the TEM images of LTO nanosheets/graphene composites. LTO nanosheets are several hundred nanometers in width and a few nanometers in thickness (Fig. 6b). Further, a LTO/GF electrode was combined with a LFP/GF to form a flexible full Li-ion battery (Fig. 6c). This flexible battery can smoothly drive a red LED even under bending condition, as shown in Fig. 6d. From Fig. 6e and Fig. 6f, it can be seen that the discharge/charge curves and cyclic stability of flexible battery are barely affected by external bendable stress, thus demonstrating its good flexible electrical stability. Moreover, Gwon et al. reported a flexible Lion battery composed of bendable graphene paper and $\mathrm{V}_{2} \mathrm{O}_{5}$ /graphene paper as anode and 
cathode, respectively, as illustrated in Fig. 7a-7c [62]. Here, the graphene paper made via a vacuum filtration and $\mathrm{V}_{2} \mathrm{O}_{5}$ films can be grown onto graphene paper by using a pulsed laser deposition (PLD) in a vacuum chamber. The flexible battery can be discharged and charged when rolled up, revealing its potential feasibility in flexible electronics (Fig. 7b). The $\mathrm{V}_{2} \mathrm{O}_{5}$ /graphene paper electrode showed better performance in terms of capacity, rate capability as well as cycling life, compared to non-flexible traditional $\mathrm{V}_{2} \mathrm{O}_{5} / \mathrm{Al}$ foil electrode (Fig. $7 \mathrm{~d}$ and 7e). In addition, Noerochim et al. introduced highly flexible binder-free $\mathrm{MoO}_{3}$ nanobelt/graphene film electrode into fabrication of bendable Li-ion batteries via a two-step micro-wave hydrothermal method [63]. The as-prepared flexible $\mathrm{MoO}_{3} /$ graphene hybrid electrodes showed excellent rate capability, enhanced capacity, and superior cyclic stability, compared to the sole $\mathrm{MoO}_{3}$ electrodes. The progresses in flexible 2D graphene-based composite cathodes can be combined with graphene-based composite anodes mentioned above.

\section{Flexible two-dimensional inorganic nanosheets-based electrodes for $\mathbf{L i}$-ion batteries}

With rapid development of battery technology, the scope of 2D nanosheets used in energy storage devices is not limited only to above graphene sheets. Recently, many promising 2D inorganic nanomaterials were further developed as well since 2D sheet-like nanomaterials with unique characteristics illustrated excellent electrochemical properties for energy storage devices. In particular, most researchers focused on flexible electrodes based on oxide nanosheets, sulfide nanosheets, multiple-compound nanosheets for future bendable lithium-ion batteries.

\subsection{Flexible two-dimensional oxide nanosheets composites}

In general, preparation of oxide nanomaterials can be regarded as a facile, environment-friendly, 
low-cost route. Many efforts on fabrication of oxide nanosheets have been disclosed for lithiumion batteries, such as porous $\mathrm{NiO}$ nanosheets/graphene synthesized by electrostatic interaction [65], porous $\mathrm{Fe}_{2} \mathrm{O}_{3}$ nanosheets synthesized by solvothermal approach followed by annealing [66], porous $\mathrm{Co}_{3} \mathrm{O}_{4}$ nanosheets synthesized by hydrothermal process [67], polythiophene (PTh)-coated $\mathrm{MnO}_{2}$ nanosheets prepared by aqueous/organic interfacial synthesis [68], $\mathrm{SnO}_{2}$ nanosheet arrays/Ti foil prepared by solution method followed by annealing [69]. Compared to the 2D nanosheets applied in the traditional non-flexible energy devices, only a few literatures regarding oxide nanosheets for flexible Li-ion batteries were reported. For example, Li et al. proposed the an anisotropic flexible electrode fabricated by controlling the growth of $\mathrm{TiO}_{2}$ nanosheets parallel to the surface of the graphene paper, which results in the $\mathrm{Li}^{+}$ion insertion and diffusion being anisotropic, as shown Fig. 8a and 8b [70]. The optical image shows an as-synthesized anisotropic flexible electrode (Fig. 8c). $\mathrm{TiO}_{2}$ sheets directly were grown on graphene paper to form a flexible anode, as shown in Fig. 9d. The cycling performance at $10 \mathrm{C}$ between the $\mathrm{TiO}_{2}$ nanosheets/graphene and $\mathrm{TiO}_{2}$ spheres/graphene electrodes, $\mathrm{TiO}_{2}$ nanosheets/graphene anodes delivered around 150 mAh g-1 over 100 cyclic times, which exhibits superior cyclic stability than $\mathrm{TiO}_{2}$ spheres/graphene composites (Fig. 8e). This is consistent with above-mentioned cell operation schematic of both $\mathrm{TiO}_{2}$ samples (Fig. 8a and 8b). Also, Liu et al. designed $\mathrm{TiO}_{2}$ nanosheets/activated carbon fabric (ACF) electrodes [71]. Firstly, fabrication of the ACF by electrospinning and thermal activation in $\mathrm{CO}_{2}$ was conducted. Then, $\mathrm{TiO}_{2}(\mathrm{~B})$ nanosheets were deposited onto carbon fabric film using hydrolysis approach followed by thermal annealing. The photograph of an as-prepared electrode shows its free-standing, flexible properties (Fig. 9a). These bendable electrodes can be easily punched into disc electrodes to fit for the coin-cell size, as shown in Fig. 9b. Clearly, numerous fibers from non-woven ACF were coated with 2D 
uniform $\mathrm{TiO}_{2}$ nanosheets, thus facilitating enhancement in electrical contact between $\mathrm{TiO}_{2}$ active materials and carbon substrate (Fig. 9c-9e). The charge/discharge profiles of $\mathrm{TiO}_{2}(\mathrm{~B}) / \mathrm{ACF}$ electrodes indicate the large capacity loss in the first cycle due to the interfacial reaction between $\mathrm{TiO}_{2}$ (B) and the $\mathrm{LiPF}_{6}$-based electrolyte, which should be common phenomenon for most lithium-intercalation hosts (Fig. 9f). After 1000 cycles, the specific capacity of $\mathrm{TiO}_{2}$ (B)/ACF electrodes still be close to $200 \mathrm{mAh} \mathrm{g}^{-1}$ (85\% capacity retention). Corresponding coulombic efficiency (CE) can maintain around $100 \%$ as well, except for initial several cycles (Fig. 9g). From this plot, it can be also seen that the contribution of bare ACF to total capacity is negligible. Compared to anatase $\mathrm{TiO}_{2}$ nanoparticles-based electrodes, $\mathrm{TiO}_{2}(\mathrm{~B})$ nnaosheets/ACF electrodes demonstrate enhanced rate-capability, as well as even hold stable cycling at $20 \mathrm{C}$ for 2000 cycles (Fig. 9h, and 9i, respectively). In this study, this type of flexible electrodes would hold a great potential for the development of flexible energy storage units with high power and energy densities.

Moreover, Liu et al. proposed a free-standing flexible $\mathrm{CuO}$ nanosheets (NSs)/r-GO composites fabricated by a vacuum filtration method and hydrothermal reduction process, as illustrated in Fig. 10a [72]. CuO NSs can be uniformly incorporated between r-GO layers, which seem like layer-by-layer sandwiched architecture (Fig. 10b and 10c). Within, r-GO layers can act as mechanical supporting and current collector. Fig. 10c inset demonstrates the photo of as-obtained highly flexible $\mathrm{CuO}$ NSs/r-GO composite electrode. Corresponding cyclic performance of $\mathrm{CuO}$ NSs/r-GO, bare CuO NSs, bare r-GO electrodes at a current density of $67 \mathrm{~mA} \mathrm{~g}^{-1}$ (Fig. 10d). These $\mathrm{CuO}$ NSs/r-GO flexible electrode can deliver the highest retaining discharge capacity (736.8 $\mathrm{mAh} \mathrm{g}^{-1}$ ), which is much higher than that of CuO NSs-based electrodes. In addition, the discharge capacity of bare r-GO electrode is close to $60 \mathrm{mAh} \mathrm{g}^{-1}$ after 50 cycles, thus revealing 
that the total discharge capacity of $\mathrm{CuO}$ NSs/r-GO electrode should be mainly attributed to contribution of $\mathrm{CuO}$ NSs.

\subsection{Flexible two-dimensional sulfide nanosheets composites}

In addition to the 2D oxide-based nanomaterials, fabrication of many sulfide-based 2D materials applied for rechargeable Li-ion batteries also attracted significant attentions. Here, $\mathrm{MoS}_{2}$ has been considered as a potential candidate for electrode materials in Li-ion batteries due to its layered structure and high theoretical capacity. Thus, many interesting $\mathrm{MoS}_{2}$ nanosheets-based electrodes were synthesized using glucose-assisted hydrothermal method [73], solvothermal reaction at a low temperature [74], template-assisted strategy [75], hydrothermal process followed by annealing [76], coprecipitation combined with solvothermal route [77]. Furthermore, $\mathrm{SnS}_{2}$ nanosheets/MWCNTs coaxial nanocables were prepared via a modified layerby-layer assembly approach [78].

It is highly expected that some functional 2D sulfide nanosheets have been introduced into the studies on the flexible electrodes for potential bendable lithium-ion batteries. $\mathrm{Li}$ et al. deposited 2D $\mathrm{MoS}_{2}$ nanosheets onto the carbon nanotube paper by a hydrothermal method to achieve flexible free-standing composite electrodes (Fig. 11a) [79]. From Fig. 11b and 11c, it can be seen that $\mathrm{MoS}_{2}$ nanosheets were uniformly incorporated with carbon nanotubes. Fig. 11d shows the EDX mapping images of the elements carbon, molybdenum, and sulfur, it can be seen that the homogeneous distribution of molybdenum and sulfur is well matched with the outline of the carbon nanotube. Additionally, the $\mathrm{MoS}_{2}$ nanosheets/carbon nanotube paper electrodes indicated a higher capacity of 1053, 1040, 1014, 975, 918, 856, 762, and $684 \mathrm{mAh} \mathrm{g}^{-1}$ at a current density of $0.05,0.1,0.2,0.5,1,2,5$, and $10 \mathrm{~A} \mathrm{~g}^{-1}$, respectively, as shown in Fig. 11e. This 
reflects the superior rate capability of $\mathrm{MoS}_{2}$ nanosheets/carbon nanotube paper electrodes, compared to that of control bulk $\mathrm{MoS}_{2}$ electrodes. After 100 cycles, the discharge capacity of $\mathrm{MoS}_{2}$ nanosheets/carbon nanotube paper electrodes still be close to $1100 \mathrm{mAh} \mathrm{g}^{-1}$ with a capacity retention of $90 \%$ for the initial discharge capacity (Fig. 11f). In comparison, these bulk $\mathrm{MoS}_{2}$ electrodes showed rapidly capacity-fading during 100 cycles. High performance $\mathrm{MoS}_{2}$ nanosheets/carbon nanotubes composite electrode would hold a potential application for flexible Li-ion batteries.

In the recent literature, Balogun et al. proposed a vanadium nitride supported $\mathrm{SnS}_{2}$ nanosheets flexible electrodes for lithium-ion batteries [80]. Briefly, a highly flexible carbon cloth (CC) film was firstly coated vanadium nitride (VN) nanowires through hydrothermal and annealing processes. Then, as-obtained CC-VN composite was immersed into a solution of $\mathrm{SnCl}_{4}$ and L-cysteine at $180{ }^{\circ} \mathrm{C}$ for $6 \mathrm{~h}$ to make $\mathrm{SnS}_{2}$ nanosheets coated onto the CC-VN surface. The total two-step growth process can be found in Fig. 12a. The corresponding SEM and optical images of bare CC, CC-VN, and CC-VN/SnS ${ }_{2}$ are also provided in Fig. 12b and its inset, Fig.12c and its inset, and Fig. 12d and its inset, respectively. Considering well-known woven carbon cloth substrate with excellent flexibility, carbon cloth coated $\mathrm{VN} / \mathrm{SnS}_{2}$ still can hold bendable/stretchable features for potential application in flexible Li-ion batteries. Clearly, CC$\mathrm{VN} / \mathrm{SnS}_{2}$ nanosheets electrodes indicate excellent cyclic stability (up to 100 cycles), as shown in Fig. 12e. After 100 cycles, the discharge capacity of CC-VN/SnS 2 , CC-VN, and CC-SnS 2 electrodes are $791 \mathrm{mAh} \mathrm{g}^{-1}, 322 \mathrm{mAh} \mathrm{g}^{-1}$, and $270 \mathrm{mAh} \mathrm{g}^{-1}$, respectively. Moreover, the CCVN@SnS $S_{2}$ electrodes show superior rate capability over the CC-VN, and CC-SnS ${ }_{2}$ electrodes (Fig. 12f).

\subsection{Flexible two-dimensional multiple-compound nanosheets composites}


Recent progresses in multiple-compound nanosheets as electrodes for lithium ion batteries, such as $\mathrm{Li}_{4} \mathrm{Ti}_{5} \mathrm{O}_{12}$ nanosheets [81,82], $\mathrm{Li}_{2} \mathrm{FeSiO}_{4}$ ultrathin nanosheets [83], and $\mathrm{LiFePO}_{4}$ nanosheets [84], have already been disclosed. The multiple-compound containing two or more types of metal ions deliver enhanced electrochemical performance due to their synergetic effects upon charge-discharge process $[85,86]$. Further, with the rapid development of traditional non-flexible Li-ion battery based multiple-compound nanosheets, some multiple-compound nanosheets-based flexible electrodes were also successfully achieved. For example, Xiong et al. designed allnanosheet-based Li-ion full battery using $\mathrm{ZnMn}_{2} \mathrm{O}_{4}$-graphene hybrid nanosheet and $\mathrm{LiFePO}_{4}$ nanosheet as anode and cathode [87], respectively, on basis of previous synthesized methods $[88,89] . \mathrm{ZnMn}_{2} \mathrm{O}_{4}$ nanocrystals were well dispersed on the surface of 2D graphene nanosheets to form $\mathrm{ZnMn}_{2} \mathrm{O}_{4}$-graphene composite nanosheets, as shown in Fig. 13a. The as-synthesized $\mathrm{LiFePO}_{4}$ nanosheets with thickness of 30 60 nm have uniform morphology (Fig. 13b). Further, Fig. 13c indicates the galvanostatic discharge/charge measurements, which reveals that the 2D $\mathrm{ZnMn}_{2} \mathrm{O}_{4}$-graphene composite electrodes delivered much larger specific capacity, enhanced rate capability and superior cyclic stability, compared to those of traditional graphite electrodes. Moreover, authors moved the $\mathrm{LiFePO}_{4}$ nanosheet cathodes into the half-cells to measure rate capability, as disclosed in Fig. 13d. Compared to commercial $\mathrm{LiFePO}_{4}, 2 \mathrm{D} \mathrm{LiFePO}_{4}$ nanosheets showed better rate performance due to the $\mathrm{LiFePO}_{4}$ nanosheets with high oriented $\left\{\begin{array}{lll}0 & 1 & 0\end{array}\right\}$ surface could supply increased active surface area and shortened $\mathrm{Li}^{+}$diffusion pathways [90,91]. Based on these half-cells, the 2D $\mathrm{ZnMn}_{2} \mathrm{O}_{4}$-graphene composite anode and 2D $\mathrm{LiFePO}_{4}$ nanosheets cathode were transferred into flexible/bendable full Li-ion batteries. This flexible battery exhibited excellent electrochemical stability without structural failure and capacity/CE loss under various mechanical bending states (Fig. 13e-13i). In addition to above all-nanosheet- 
based flexible batteries, Hou et al. conducted successfully $2 \mathrm{D} \mathrm{MnCo}_{2} \mathrm{O}_{4}$ nanosheets grown on the highly stretchable carbon cloth using hydrothermal method for flexible Li-ion batteries [92]. The binder-free $\mathrm{MnCo}_{2} \mathrm{O}_{4}$ nanosheets/carbon cloth composite electrodes delivered stable cycle life (over 60 times), enhanced rate capability, as well as highest areal capacity than that reported in previous literatures [93-95].

Using a simple and scalable process, $\mathrm{Li}$ et al. synthesized $\mathrm{Li}_{4} \mathrm{Ti}_{5} \mathrm{O}_{12}$ (LTO) nanosheets with $\mathrm{N}$ doped carbon coating (denoted C-LTO nanosheets), as shown in Fig. 14a and 14b [96]. Afterwards, a self-standing flexible C-LTO nanosheets-based film was fabricated by vacuumfiltration on a Whatman polycarbonate track-etched membrane, which can guarantee interwoven and mechanically robust LTO nanosheet film attached to this membrane (Fig. 14c and 14d). Galvanostatic discharge/charge voltage profiles of C-LTO nanosheets, LTO nanosheets, and nano-LTO electrodes with a wide range from 1C to 100C were also estimated in Fig. 10e. Compared to both LTO nanosheets and nano-LTO electrodes, C-LTO nanosheets electrodes showed an excellent rate performance and a good cycling stability due to the thin uniform carbon layer and the porous structure existed in C-LTO film, which offers more highly conductive pathways for electrons and fast transport channels for $\mathrm{Li}^{+}$.

\section{Challenges and perspectives}

With the rapid development of lightweight, flexible, and wearable electronic devices, flexible and highly efficient energy units are urgently needed. 2D nano-materials introduced in this article include graphene paper, graphene composites, and representative inorganic-material nanosheets. A summary regarding flexible electrode based on 2D nanomaterials for Li-ion batteries can be

found as well in Table 1. Although 2D nanomaterials have been widely studied for the 
applications in many fields such as supercapacitor, Li-ion battery, catalysis, metal-air battery, Naion battery [18,75-77,97-99], its application in flexible energy storage devices, especially flexible Li-ion batteries is still an emerging filed. In the case of flexible battery, except for improvement of electro-chemical performance, it is crucial to maintain the excellent stability in terms of electric, capacity, and voltage for these as-prepared flexible batteries under bending. To fulfill these targets, the enhanced adhesion between active materials/flexible current collectors, improved conductivity of the whole flexible electrode as well as optimized design of 2D nanomaterials should be required as well. The main challenges and perspectives in this filed include the following aspect:

(1) Most research works have focused on the preparation and characterizations of a single flexible electrode. Preparation of the complete flexible battery in a coherent approach is urgently needed.

(2) More attentions should be paid to develop more efficient and scalable approach to make unique 2D nanomaterial-based electrode and a better matched flexible Li-ion batteries, especially flexible batteries based on new chemistries.

(3) So far, most characterization of 2D nanomaterial-based flexible Li-ion batteries still focus on the battery level performance. Herein, more in-depth studies, including in situ characterization of charge/discharge processes of 2D nanomaterial-based flexible Li-ion batteries are required to further reveal the intrinsic limitation of these batteries and their components, such as active nanomaterials, separator, and current collector under bending.

(4) It is worth noting that three dimensional (3D) integrated electrodes containing 3D conductive network support and active material served for energy storage devices have received increasing attention due to their unique electrochemical superiorities, i.e. great enhancement in 
effective contact area between electrolyte/active materials, high efficiency of electron/ion transport and facile diffusion of the electrolyte, and good accommodation of strain induced by the volume change during electrochemical reactions [32,100-103]. In fact, it is possible to make many functional nanosheets deposited onto suitable conductive substrates with three-dimensional structure via in-situ growth or various coating methods to maximize functions of both nanosheets with unique characters, and 3D free-standing films.

(5) Considering emerging serious battery safety concerns, the battery-research mainstream is going back to intrinsic safety issue. Thus, some recent progresses in the all solidstate battery systems, water-phase electrolyte, and solid ion conductors are being gradually disclosed. To smoothly incorporate these aforementioned components into flexible various batteries should be considered as a sweet spot in terms of flexible battery technology and chemistries.

(6) Alternative packaging materials with flexibility, lightness, thinness, stability should be also investigated to protect battery materials, electrolytes and electrochemical reactions from being affected by the external environment.

(7) The assembly technology need to be further investigated. Fabrication of free-standing supports, shape-deformable highly conductive electrolytes, and integration technologies of the full Li-ion battery need to be carefully studied.

\section{Acknowledgements}

This work was supported by the Assistant Secretary for Energy Efficiency and Renewable Energy, Office of Vehicle Technologies, the Advanced Battery Materials Research (BMR) 
programs of the U.S. Department of Energy (DOE) under contract no. DE-AC02-05CH11231, subcontract no. 18769, and the National Natural Science Foundation of China (No. 61377033).

\section{References}

[1] A. Vu, Y. Qian, A. Stein, Adv. Energy Mater. 2 (2012) 1056-1085.

[2] W. Lu, R. Hartman, J. Phys. Chem. Lett. 2 (2011) 655-660.

[3] A. Manthiram, A. Vadivel Murugan, A. Sarkar, T. Muraliganth, Energy Environ. Sci. 1 (2008) 621-638.

[4] Y. Guo, J. Hu, L. Wan, Adv. Mater. 20 (2008) 2878-2887.

[5] A. Arico, P. Bruce, B. Scrosati, J. Tarascon, W. Schalkwijk, Nat. Mater. 4 (2005) 366-377.

[6] P. Bruce, B. Scrosati, J. Tarascon, Angew. Chem. Int. Ed. 47 (2008) 2930-2946.

[7] M. Kim, J. Cho, Adv. Funct. Mater. 19 (2009) 1497-1514.

[8] B. Liu, W. Xu, P. Yan, X. Sun, M. E. Bowden, J. Read, J. Qian, D. Mei, C.-M. Wang, J.-G. Zhang, Adv. Funct. Mater. 2015, DOI:10.1002/adfm.201503697.

[9] R. Liu, J. Duay, S. Lee, Chem. Commun. 47 (2011) 1384-1404.

[10] C. Yuan, H. Wu, Y. Xie, X. W. Lou, Angew. Chem. Int. Ed. 53 (2014) 1488-1504.

[11] S. Ding, D. Zhang, J. Chen, X. W. Lou, Nanoscale 4 (2012) 95-98.

[12] J. Qian, W. Henderson, W. Xu, P. Bhattacharya, M. Engelhard, O. Borodin, J. Zhang, Nat. Commun. 6 (2015) 6362.

[13] W. Xu, J. Wang, F. Ding, X. Chen, E. Nasybulin, Y. Zhang, J. Zhang, Energy Environ. Sci. 7 (2014) 513-537.

[14] X. Wang, B. Liu, X. Hou, Q. Wang, W. Li, D. Chen, G. Shen, Nano Res. 7 (2014) 10731082. 
[15] B. Liu, B. Liu, Q. Wang, X. Wang, Q. Xiang, D. Chen, G. Shen, ACS Appl. Mater. Interfaces 5 (2013) 10011-10017.

[16] J. Chmiola, C. Largeot, P. Taberna, P. Simon, Y. Gogotsi, Science 328 (2010) 480-483.

[17] D. Pech, M. Brunet, H. Durou, P. Huang, V. Mochalin, Y. Gogotsi, P. Taberna, P. Simon, Nat. Nanotechnol. 5 (2010) 651-654.

[18] J. Feng, X. Sun, C. Wu, L. Peng, C. Lin, S. Hu, J. Yang, Y. Xie, J. Am. Chem. Soc. 133 (2011) 17832-17838.

[19] J. Sung, S. Kim, K. Lee, J. Power Sources 133 (2004) 312-319.

[20] J. Yoo, K. Balakrishnan, J. Huang, V. Meunier, B. Sumpter, A. Srivastava, M. Conway, A. L. M. Reddy, J. Yu, R. Vajtai, P. Ajayan, Nano Lett. 11 (2011) 1423-1427.

[21] B. Liu, D. Tan, X. Wang, D. Chen, G. Shen, Small 9 (2013) 1998-2004.

[22] B. Liu, B. Liu, X. Wang, X. Wu, W. Zhao, Z. Xu, D. Chen, G. Shen, Adv. Mater. 26 (2014) 4999-5004.

[23] W. Li, X. Wang, B. Liu, S. Luo, Z. Liu, X. Hou, Q. Xiang, D. Chen, G. Shen, Chem. Eur. J. 19 (2013) 8650-8656.

[24] X. Hou, B. Liu, X. Wang, Z. Wang, Q. Wang, D. Chen, G. Shen, Nanoscale 5 (2013) 78317837.

[25] S. Lee, N. Yabuuchi, B. Gallant, S. Chen, B. Kim, P. Hammond, Y. Shao-Horn, Nat. Nanotechnol. 5 (2010) 531-537.

[26] S. Lee, B. Gallant, Y. Lee, N. Yoshida, D. Kim, Y. Yamada, S. Noda, A. Yamada, Y. ShaoHorn, Energy Environ. Sci. 5 (2012) 5437-5444.

[27] J. Chen, A. I. Minett, Y. Liu, C. Lynam, P. Sherrell, C. Wang, G. G. Wallace, Adv. Mater. 20 (2008) 566-570. 
[28] B. Liu, X. Wang, B. Liu, Q. Wang, D. Tan, W. Song, X. Hou, D. Chen, G. Shen, Nano Res. 6 (2013) 525-534.

[29] L. Hu, M. Pasta, F. Mantia, L. Cui, S. Jeong, H. Deshazer, J. Choi, S. Han, Y. Cui, Nano Lett. 10 (2010) 708-714.

[30] Y. Yang, S. Jeong, L. B. Hu, H. Wu, S. W. Lee, Y. Cui, Proc. Natl. Acad. Sci. U. S. A. 108 (2011) 13013-13018.

[31] K. Evanoff, J. Benson, M. Schauer, I. Kovalenko, D. Lashmore, W. J. Ready, G. Yushin, ACS Nano 6 (2012) 9837-9845.

[32] B. Liu, J. Zhang, X. Wang, G. Chen, D. Chen, C. Zhou, G. Shen, Nano Lett. 12 (2012) 3005-3011.

[33] X. Jia, Z. Chen, A. Suwarnasarn, L. Rice, X. Wang, H. Sohn, Q. Zhang, B. Wu, F. Wei, Y. Lu, Energy Environ. Sci. 5 (2012) 6845-6849.

[34] H. Lee, J. Yoo, J. Park, J. Kim, K. Kang, Y. Jung, Adv. Energy Mater. 2 (2012) 976-982.

[35] X. Wang, B. Liu, Q. Xiang, X. Hou, D. Chen, G. Shen, ChemSusChem 7 (2014) 308-313.

[36] J. Liu, X. Liu, Adv. Mater. 24 (2012) 4097-4111.

[37] X. Wang, X. Lu, B. Liu, D. Chen, Y. Tong, G. Shen, Adv. Mater. 26 (2014) 4763-4782.

[38] S. Ju, J. Li, J. Liu, P. Chen, Y. Ha, F. Ishikawa, H. Chang, C. Zhou, A. Facchetti, D. Janes, T. Mark, Nano Lett. 8 (2008) 997-1004.

[39] X. Wang, G. Shi, Energy Environ. Sci. 8 (2015) 790-823.

[40] V. Pushparaj, M. Shaijumon, A. Kumar, S. Murugesan, L. Ci, R. Vajtai, R. Linhardt, O. Nalamasu, P. Ajayan, Proc. Natl. Acad. Sci. U. S. A. 104 (2007) 13574-13577.

[41] Y. Hu, X. Li, D. Geng, M. Cai, R. Li, X. Sun, Electrochim. Acta 91 (2013) 227-233.

[42] G. Ning, C. Xu, Y. Cao, X. Zhu, Z. Jiang, Z. Fan, W. Qian, F. Wei, J. Gao, J. Mater. Chem. 
A 1 (2013) 408-414.

[43] X. Zhao, C. Hayner, M. Kung, H. Kung, ACS Nano 5 (2011) 8739-8749.

[44] R. Mukherjee, A. Thomas, A. Krishnamurthy, N. Koratkar, ACS Nano 6 (2012) 7867-7878.

[45] A. Abouimrane, O. Compton, K. Amine, S. Nguyen, J. Phys. Chem. C 114 (2010) 1280012804.

[46] W. S. Hummers, R. E. Offman, J. Am. Chem. Soc. 80 (1958) 1339-1339.

[47] D. Li, M. Muller, S. Gilje, R. Kaner, G. Wallace, Nat. Nanotechnol. 3 (2008) 101-105.

[48] F. Liu, S. Song, D. Xue, H. Zhang, Adv. Mater. 24 (2012) 1089-1094.

[49] T. Hu, X. Sun, H. Sun, M. Yu, F. Lu, C. Liu, J. Lian, Carbon 51 (2013) 322-326.

[50] H. Ren, Y. Ding, F. Chang, X. He, J. Feng, C. Wang, Appl. Surf. Sci. 263 (2012) 54-57.

[51] X. Yang, K. Fan, Y. Zhu, J. Shen, X. Jiang, P. Zhao, S. Luan, C. Li, ACS Appl. Mater. Interfaces 5 (2013) 997-1002.

[52] J. Liang, Y. Zhao, L. Guo, L. Li, ACS Appl. Mater. Interfaces 4 (2012) 5742-5748.

[53] A. Yu, H. Park, A. Davies, D. Higgins, Z. Chen, X. Xiao, J. Phys. Chem. Lett. 2 (2011) 1855-1860.

[54] X. Huang, B. Sun, S. Chen, G. Wang, Chem. Asian J. 9 (2014) 206-211.

[55] C. Wang, Y. Chui, R. Ma, T. Wong, J. Ren, Q. Wu, X. Chen, W. Zhang, J. Mater. Chem. A. 1 (2013) 10092-10098.

[56] B. Wang, X. Li, X. Zhang, B. Luo, M. Jin, M. Liang, S. Dayeh, S. Picraux, L. Zhi, ACS Nano 7 (2013) 1437-1445.

[57] B. Liu, X. Wang, H. Chen, Z. Wang, D. Chen, Y. Cheng, C. Zhou, G. Shen, Sci. Rep. 3 (2013) 1622.

[58] J. Wang, C. Zhong, S. Chou, H. Liu, Electrochem. Commun. 12 (2010) 1467-1470. 
[59] W. Kim, W. Ryu, D. Han, S. Lim, J. Eom, H. Kwon, ACS Appl. Mater. Interfaces 6 (2014) 4731-4736.

[60] Y. Ding, H. Ren, Y. Huang, F. Chang, P. Zhang, Mater. Res. Bull. 48 (2013) 3713-3716.

[61] N. Li, Z. Chen, W. Ren, F. Li, H.-M. Cheng, Proc. Natl. Acad. Sci. U. S. A. 109 (2012) 17360-17365.

[62] H. Gwon, H. Kim, K. Lee, D. Seo, Y. Park, Y. Lee, B. Ahn, K. Kang, Energy Environ. Sci. 4 (2011) 1277-1283.

[63] L. Noerochim, J. Wang, D. Wexler, Z. Chao, H. Liu, J. Power Sources 228 (2013) 198-205.

[64] X. Zhao, C. Hayner, M. Kung, H. Kung, Chem. Commun. 48 (2012) 9909-9911.

[65] Y. Huang, X. Huang, J. Lian, D. Xu, L. Wang, X. Zhang, J. Mater. Chem. 22 (2012) 28442847.

[66] L. Li, H. B. Wu, L. Yu, S. Madhavi, X. W. Lou, Adv. Mater. Interfaces. 1 (2014) 1400050.

[67] F. Zhan, B. Geng, Y. Guo, Chem. Eur. J. 15 (2009) 6169-6174.

[68] W. Xiao, J. S. Chen, Q. Lu, X. W. Lou, J. Phys. Chem. C 114 (2010) 12048-12051.

[69] L. Zhang, H. B. Wu, X. W. Lou, Mater. Horiz. 1 (2014) 133-138.

[70] N. Li, G. Zhou, R. Fang, F. Li, H.-M. Cheng, Nanoscale 5 (2013) 7780-7784.

[71] S. Liu, Z. Wang, C. Yu, H. Wu, G. Wang, Q. Dong, J. Qiu, A. Eychmuller, X. W. Lou, Adv. Mater. 25 (2013) 3462-3467.

[72] Y. Liu, W. Wang, L. Gu, Y. Wang, Y. Ying, Y. Mao, L. Sun, X. Peng, ACS Appl. Mater. Interfaces 5 (2013) 9850-9855.

[73] S. Ding, J. Chen, X. W. Lou, Chem. Eur. J. 17 (2011) 13142-13145.

[74] M. Wang, G. Li, H. Xu, Y. Qian, J. Yang, ACS Appl. Nater. Interfaces 5 (2013) 1003-1008.

[75] L. Zhang, H. B. Wu, Y. Yan, X. Wang, X. W. Lou, Energy Environ. Sci. 7 (2014) 3302- 
3306.

[76] X. Xu, Z. Fan, X. Yu, S. Ding, D. Yu, X. W. Lou, Adv. Energy Mater. 4 (2014) 1400902.

[77] X.-Y Yu, H. Hu, Y. Wang, H. Chen, X. W. Lou, Agnew. Chem. Int. Ed. 54 (2015) 73957398.

[78] C. Zhai, N. Du, H. Zhang, J. Yu, D. Yang, ACS Appl. Mater. Interfaces 3 (2011) 4067-4074.

[79] H. Li, X. Wang, B. Ding, G. Pang, P. Nie, L. Shen, X. Zhang, ChemElectroChem 1 (2014) 1118-1125.

[80] M.-S. Balogun, W. Qiu, J. Jian, Y. Huang, Y. Luo, H. Yang, C. Liang, X. Lu, Y. Tong, ACS Appl. Mater. Interfaces 7 (2015) 23205-23215.

[81] Y. Tang, L. Yang, Z. Qiu, J. Huang, Electrochem. Commun. 10 (2008) 1513-1516.

[82] Y. Tang, F. Huang, W. Zhao, Z. Liu, D. Wan, J. Mater. Chem. 22 (2012) 11257-11260.

[83] D. Rangappa, K. D. Murukanahally, T. Tomai, A. Unemoto, I. Honma, Nano Lett. 12 (2012) 1146-1151.

[84] X. Rui, X. Zhao, Z. Lu, H. Tan, D. Sim, H. H. Hng, R. Yazami, T. M. Lim, Q. Yan, ACS Nano 7 (2013) 5637-5646.

[85] H. Wang, Y. Yang, Y. Liang, G. Zheng, Y. Li, Y. Cui, H. Dai, Energy Environ. Sci. 5 (2012) 7931-7935.

[86] L. Wang, B. Liu, S. Ran, L. Wang, L. Gao, F. Qu, D. Chen, G. Shen, J. Mater. Chem. A 1, (2013) 2139-2143.

[87] P. Xiong, L. Peng, D. Chen, Y. Zhao, X. Wang, G. Yu, Nano Energy 12 (2015) 816-823.

[88] P. Xiong, B. Liu, V. Teran, Y. Zhao, L. Peng, X. Wang, G. Yu, ACS Nano 8 (2014) 86108616.

[89] Y. Zhao, L. Peng, B. Liu, G. Yu, Nano Lett. 14 (2014) 2849-2853. 
[90] L. Wang, X. He, W. Sun, J. Wang, Y. Li, S. Fan, Nano Lett. 12 (2012) 5632-5636.

[91] R. Malik, D. Burch, M. Bazant, G. Ceder, Nano Lett. 10 (2010) 4123-4127.

[92] X. Hou, X. Wang, B. Liu, Q. Wang, T. Luo, D. Chen, G. Shen, Nanoscale 6 (2014) 88588864.

[93] X. Hou, X. Wang, B. Liu, Q. Wang, Z. Wang, D. Chen, G. Shen, ChemElectroChem 1 (2014) 108-115.

[94] W. Ren, C. Wang, L. Lu, D. Li, C. Cheng, J. Liu, J. Mater. Chem. A 1 (2013) 13433-13438.

[95] L. Yu, L. Zhang, H. B. Wu, G. Zhang, X. W. Lou, Energy Environ. Sci. 6 (2013) 26642671.

[96] N. Li, G. Zhou, F. Li, L. Wen, H.-M. Cheng, Adv. Funct. Mater. 23 (2013) 5429-5435.

[97] Y. Sun, S. Gao, F. Lei, Y. Xie, Chem. Soc. Rev. 44 (2015) 623-636.

[98] B. Liu, W. Xu, P. Yan, P. Bhattacharya, R. Cao, M. E. Bowden, M. H. Engelhard, C.-M. Wang, J.-G. Zhang, ChemSusChem 8 (2015) 3697-3703.

[99] H. Wang, Z. Wu, F. Meng, D. Ma, X. Huang, L. Wang, X. Zhang, ChemSusChem 6 (2013) 56-60.

[100] X. Xia, D. Chao, Y. Zhang, Z. X. Shen, H. J. Fan, Nano Today 9 (2014) 785-807.

[101] J. Liu, J. Jiang, C. Cheng, H. Li, J. Zhang, H. Gong, H. J. Fan, Adv. Mater. 23 (2011) 2076-2081.

[102] B. Liu, T. Luo, G. Mu, X. Wang, D. Chen, G. Shen, ACS Nano 7 (2013) 8051-8058.

[103] X. Xia, Y. Zhang, Z. Fan, D. Chao, Q. Xiong, J. Tu, H. Zhang, H. J. Fan, Adv. Energy Mater. 5 (2015) 1401709. 


\section{Figure Captions:}

Figure 1 An overview of flexible lithium battery electrodes based on 2D graphene paper, 2D graphene/active cathode-material, 2D graphene/active anode-materials, and various 2D inorganic nanosheets/carbon composites.

Figure 2 Schematic illustrations of the laser reduction system with the raster scan path (a), and (b) the flash reduction of graphene oxide whereby a flash from a digital camera reduces graphene oxide. (c) Photograph of the flash-reduced graphene. (d) Scanning electron microscopy (SEM) image of the two characteristic regions of flash-reduced graphene and graphene oxide. (e) The cycling stability measurement of flash-reduced graphene. Reproduced with the permission from Ref. [44].

Figure 3 (a-c) The optical images of as-prepared graphene paper. (d) The SEM image of graphene paper. (e) The discharge/charge curves of flexible graphene paper electrodes. (f) Corresponding rate capability. Reproduced with the permission from Ref. [48].

Figure 4 FESEM images of cross-section (a-c), top-view (d, e) of the graphene/SnO $\mathrm{C}_{2} \mathrm{composite}$ paper. (f) The optical image of as-prepared composite paper. (g) The cycling performance of graphene/ $\mathrm{SnO}_{2}$, and bare $\mathrm{SnO}_{2}$ electrodes. (h) Nyquist plots of graphene/ $\mathrm{SnO}_{2}$, and bare $\mathrm{SnO}_{2}$ electrodes. Reproduced with the permission from Ref. [52].

Figure 5 (a) Low magnification SEM image of SiNW@G@RGO electrode. The inset: an optical image of a bent SiNW@G@RGO film with excellent flexibility. (b) Cross-section and (c) topsurface SEM images of SiNW@G@RGO electrode. (d) The corresponding region for collecting 
EDX spectrum in (e). Reproduced with the permission from Ref. [56].

Figure 6 (a) The TEM image of the as-synthesized LTO/GF composites. (b) TEM image of the LTO nanosheets in LTO/GF. (c) Photograph of a bent LTO/GF//LFP/GF full battery encapsulated by PDMS, showing its good flexibility. (d) Optical image of a flexible Li-ion battery lighting a red LED device. (e) Galvanostatic charging/discharging curves of the battery. (f) Cyclic performance of the battery under flat and bent states. Reproduced with the permission from Ref. [61].

Figure 7 (a, b) The Photographs of a free-standing flexible $\mathrm{V}_{2} \mathrm{O}_{5}$ /graphene-based battery. (c) Schematic drawing of the flexible Li battery. (d) The rate capability of $\mathrm{V}_{2} \mathrm{O}_{5} /$ graphene paper and $\mathrm{V}_{2} \mathrm{O}_{5} / \mathrm{Al}$ foil electrodes at different charge/discharge rates. (e) Their corresponding cycling performance at 1C charge-discharge rates. Reproduced with the permission from Ref. [62].

Figure 8 The schematic of the structure and cell operation of $\mathrm{TiO}_{2}$ nanosheets/graphene (a), and $\mathrm{TiO}_{2}$ spheres/graphene (b). (c) The optical image of $\mathrm{TiO}_{2}$ nanosheets/graphene with good flexibility. (d) The corresponding SEM image of $\mathrm{TiO}_{2}$ nanosheets deposited into graphene. (e) The electrochemical measurements of $\mathrm{TiO}_{2}$ nanosheets/graphene, and $\mathrm{TiO}_{2}$ spheres/graphene electrodes. Reproduced with permission. Reproduced with the permission from Ref. [70].

Figure 9 (a) Optical image of free-standing as-fabricated rolled-up $\mathrm{TiO}_{2}$ (B)/non-woven activated carbon fabric (ACF). (b) Photo of one $\mathrm{TiO}_{2}$ (B)/ACF composite disc electrode. (c-e) Different magnification FESEM images of $\mathrm{TiO}_{2}$ (B)/ACF composite electrodes. (f) Charge- 
discharge profiles of $\mathrm{TiO}_{2}$ (B)/ACF composite electrodes for the $1^{\text {st }}, 2^{\text {nd }}$, and $1000^{\text {th }}$ cycles. (g) Cycling performance and Coulombic efficiency of the $\mathrm{TiO}_{2}$ (B)/ACF electrodes and ACF only electrodes between 1.0-3.0 $\mathrm{V}$ at a current density of $335 \mathrm{~mA} \mathrm{~g}^{-1}$. (h) The rate capability of $\mathrm{TiO}_{2}$ (B)/ACF electrode, and anatase $\mathrm{TiO}_{2}$ nanoparticles between 1.0-3.0 $\mathrm{V}$ at varied current rates of 130 C. (i) Long-term cycling performance and corresponding Coulombic efficiency of the $\mathrm{TiO}_{2}$ (B)/ACF electrode at 20 C for 2000 cycles. Reproduced with the permission from Ref. [71].

Figure 10 (a) Schematic of the synthsis of CuO nanosheets (NSs)/r-GO paper. (b,c) Crosssection SEM images of the CuO NSs/r-GO composites. Inset: a optical image of an as-prepared free-standing $\mathrm{CuO}$ NSs/r-GO electrode, showing its good flexibility. (d) Electrochemical characterizations of $\mathrm{CuO} \mathrm{NSs/r-GO}$, bare $\mathrm{CuO} \mathrm{NSs}$, and bare r-GO electrodes for Li-ion batteries. Reproduced with the permission from Ref. [72].

Figure 11 (a) Schematic illustration of the fabrication of flexible $\mathrm{MoS}_{2}$ nanosheets/carbon nanotube paper. (b,c) TEM images of resulting $\mathrm{MoS}_{2}$ nanosheets/carbon nanotube paper composites. (d) The corresponding EDX mapping. The rate capability performance (e), and cyclic life measurements (f) of $\mathrm{MoS}_{2}$ nanosheets/carbon tube paper and bulk $\mathrm{MoS}_{2}$, respectively. Reproduced with the permission from Ref. [79].

Figure 12 (a) Schematic illustration of the two-step fabrication process of flexible electrodes composed of carbon cloth (CC)-vanadium nitride $(\mathrm{VN}) / \mathrm{SnS}_{2}$ nanosheets composites. SEM images of (b) the bare CC, (c) VN deposited on the CC, (d) $\mathrm{VN} / \mathrm{SnS}_{2}$ on the CC. Insets: corresponding optical images of bare CC, CC/VN, CC-VN/SnS ${ }_{2}$. (e) Cycling perforamcne of 
various three electrodes (CC-VN/SnS 2 , CC-VN, and CC-SnS ${ }_{2}$ ) at a current density of $0.65 \mathrm{~A} \mathrm{~g}^{-1}$. (f) Rate capability of $\mathrm{CC}-\mathrm{VN} / \mathrm{SnS}_{2}, \mathrm{CC}-\mathrm{VN}$, and $\mathrm{CC}-\mathrm{SnS}_{2}$ electrodes at different rates. Reproduced with the permission from Ref. [80].

Figure $13(\mathrm{a}, \mathrm{b})$ The SEM images of 2D $\mathrm{ZnMn}_{2} \mathrm{O}_{4}$-graphene composite nanosheets and 2D $\mathrm{LiFePO}_{4}$ nanosheets, respectively. (c) The rate capability of as-synthesized $2 \mathrm{D} \mathrm{ZnMn}_{2} \mathrm{O}_{4^{-}}$ graphene composite, and graphite only electrodes. (d) The rate capability of the as-prepared $\mathrm{LiFePO}_{4}$ nanosheets, and commercial $\mathrm{LiFePO}_{4}$ powder. Reproduced with the permission from Ref. [87].

Figure 14 (a) The TEM images of the C-LTO nanosheets. (b) HRTEM image of the C-LTO nanosheets, clearly showing some carbon layers incorporated with LTO nanosheets. (c) Optical image of a free-standing highly flexibly C-LTO film. (d) Cross-section SEM image of C-LTO nanosheet film electrode. (e) Galvanostatic discharge/charge voltage profiles of C-LTO nanosheets, LTO nanosheets as well as nano-LTO electrodes cycled at different rates (1C, 5C, 10C, 50C, and 100C). Print with the permission from Ref. [96]. 


\section{Table}

Table 1 Main parameters of 2D nanomaterials-based electrodes for flexible lithium-ion batteries.

\begin{tabular}{|c|c|c|c|c|c|}
\hline nanosheets-based electrode & synthesis method & cycling life & capacity retention & current density & Ref. \\
\hline Graphene paper & $\begin{array}{c}\text { photothermal } \\
\text { reduction } \\
\end{array}$ & 1000 & $156 \mathrm{mAh} \mathrm{g}^{-1}$ & $14880 \mathrm{~mA} \mathrm{~g}^{-1}$ & 44 \\
\hline Graphene paper & freeze-drying & 100 & $560 \mathrm{mAh} \mathrm{g}^{-1}$ & $100 \mathrm{~mA} \mathrm{~g}^{-1}$ & 48 \\
\hline $\begin{array}{c}\text { Graphene/ } / \mathrm{TiO}_{2} \\
\text { nanoparticles } \\
\end{array}$ & filtration & 100 & $157 \mathrm{mAh} \mathrm{g}^{-1}$ & $200 \mathrm{~mA} \mathrm{~g}^{-1}$ & 49 \\
\hline $\begin{array}{c}\text { Graphene paper/ } / \mathrm{Co}_{3} \mathrm{O}_{4} \\
\text { fibers }\end{array}$ & $\begin{array}{l}\text { electrostatic } \\
\text { interactions }\end{array}$ & 40 & $840 \mathrm{mAh} \mathrm{g}^{-1}$ & $100 \mathrm{~mA} \mathrm{~g}^{-1}$ & 51 \\
\hline $\begin{array}{c}\text { Graphene paper/SnO } \\
\text { nanoparticles } \\
\end{array}$ & filtration & 50 & $438 \mathrm{mAh} \mathrm{g}{ }^{-1}$ & $100 \mathrm{~mA} \mathrm{~g}^{-1}$ & 52 \\
\hline $\begin{array}{c}\text { Graphene paper/ } \mathrm{Fe}_{3} \mathrm{O}_{4} \\
\text { nanoparticles } \\
\end{array}$ & wet-immersion & 100 & $1427.5 \mathrm{mAh} \mathrm{g}^{-1}$ & $1000 \mathrm{~mA} \mathrm{~g}^{-1}$ & 54 \\
\hline RGO/G/Si nanowire & $\begin{array}{c}\text { chemical vapor } \\
\text { deposition } \\
\end{array}$ & 50 & $1650 \mathrm{mAh} \mathrm{g}^{-1}$ & $840 \mathrm{~mA} \mathrm{~g}^{-1}$ & 56 \\
\hline Graphene/ $\mathrm{MoO}_{3}$ nanobelts & $\begin{array}{c}\text { microwave } \\
\text { hydrothermal }\end{array}$ & 100 & $172 \mathrm{mAh} \mathrm{g}{ }^{-1}$ & $100 \mathrm{~mA} \mathrm{~g}^{-1}$ & 63 \\
\hline $\mathrm{TiO}_{2}$ nanosheets/graphene & hydrothermal & 100 & $147 \mathrm{mAh} \mathrm{g}^{-1}$ & $1680 \mathrm{~mA} \mathrm{~g}^{-1}$ & 70 \\
\hline $\begin{array}{c}\mathrm{TiO}_{2} \text { nanosheets/activated } \\
\text { carbon fabric } \\
\end{array}$ & hydrothermal & 1000 & $200 \mathrm{mAh} \mathrm{g}^{-1}$ & $335 \mathrm{~mA} \mathrm{~g}^{-1}$ & 71 \\
\hline $\mathrm{CuO}$ nanosheets/r-GO & hydrothermal & 50 & $736.5 \mathrm{mAh} \mathrm{g}^{-1}$ & $67 \mathrm{~mA} \mathrm{~g}^{-1}$ & 72 \\
\hline $\begin{array}{c}\mathrm{MoS}_{2} \text { nanosheets/carbon } \\
\text { nanotube } \\
\end{array}$ & hydrothermal & 100 & $1091 \mathrm{mAh} \mathrm{g}^{-1}$ & $100 \mathrm{~mA} \mathrm{~g}^{-1}$ & 79 \\
\hline $\begin{array}{c}\mathrm{SnS}_{2} \text { nanosheets/carbon } \\
\text { cloth } \\
\end{array}$ & hydrothermal & 100 & $791 \mathrm{mAh} \mathrm{g}^{-1}$ & $650 \mathrm{~mA} \mathrm{~g}^{-1}$ & 80 \\
\hline $\begin{array}{c}\mathrm{ZnMn}_{2} \mathrm{O}_{4} \\
\text { nanosheets/graphene }\end{array}$ & refluxing & 100 & $734 \mathrm{mAh} \mathrm{g}^{-1}$ & $400 \mathrm{~mA} \mathrm{~g}^{-1}$ & 87 \\
\hline $\begin{array}{c}\mathrm{MnCo}_{2} \mathrm{O}_{4} \\
\text { nanosheets/carbon cloth }\end{array}$ & hydrothermal & 60 & $3 \mathrm{mAh} \mathrm{cm}^{-2}$ & $800 \mu \mathrm{A} \mathrm{cm} \mathrm{cm}^{-2}$ & 92 \\
\hline $\begin{array}{c}\mathrm{Li}_{4} \mathrm{Ti}_{5} \mathrm{O}_{12} \text { nanosheets/N- } \\
\text { doped carbon }\end{array}$ & annealing treatment & 100 & $152 \mathrm{mAh} \mathrm{g}^{-1}$ & $1750 \mathrm{~mA} \mathrm{~g}^{-1}$ & 96 \\
\hline
\end{tabular}


Figures

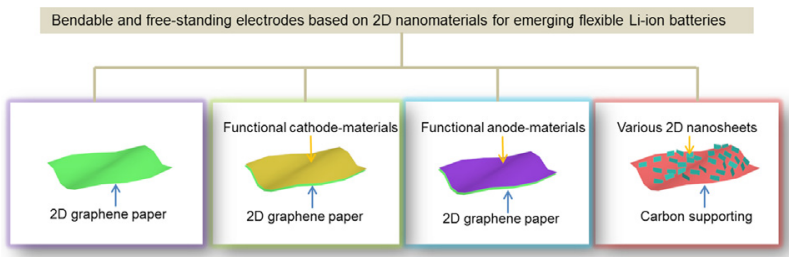

Figure 1. / by Guozhen Shen et al.

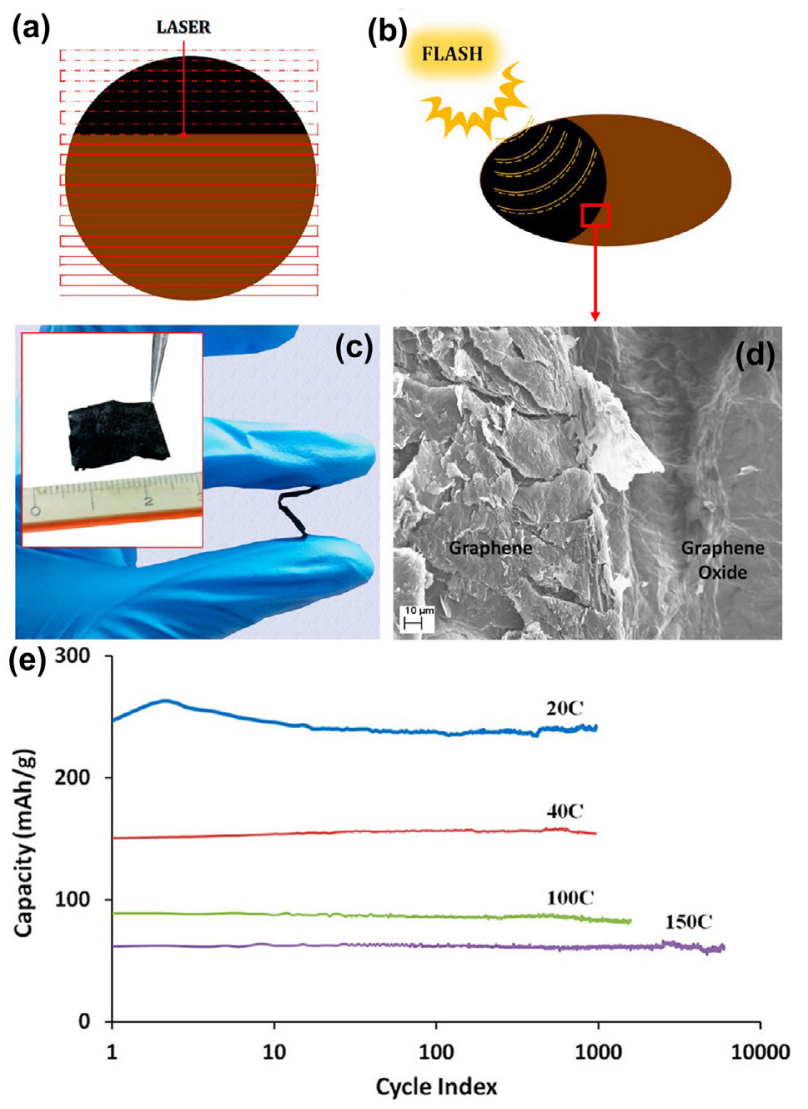

Figure 2. / by Guozhen Shen et al. 

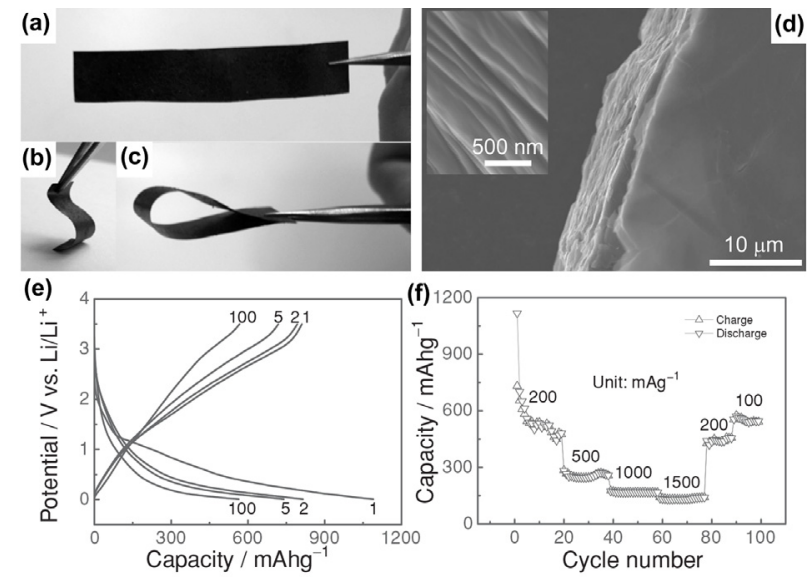

Figure 3. / by Guozhen Shen et al.

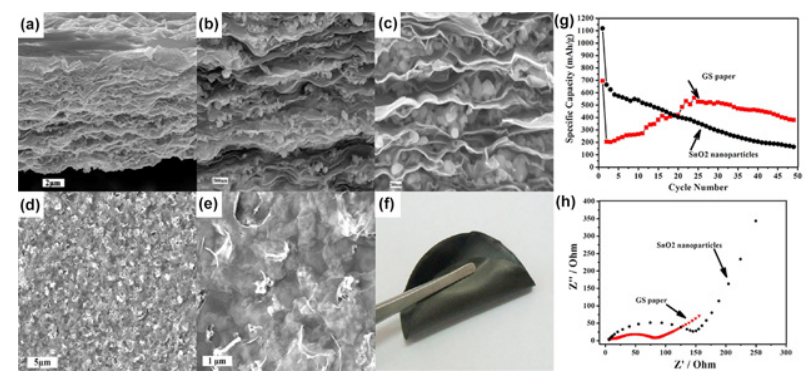

Figure 4. / by Guozhen Shen et al. 


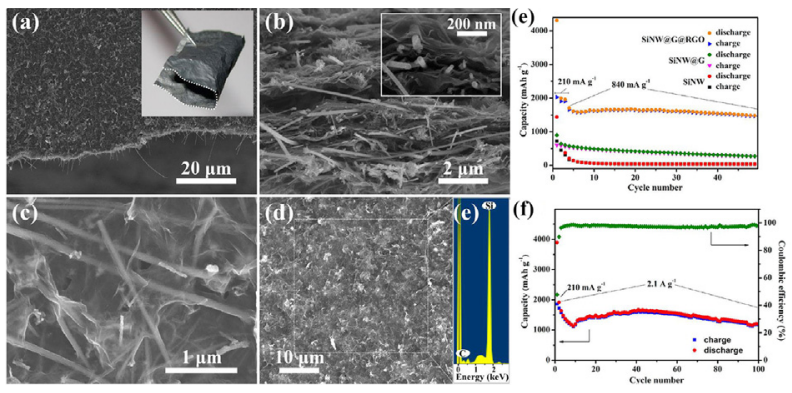

Figure 5. / by Guozhen Shen et al.
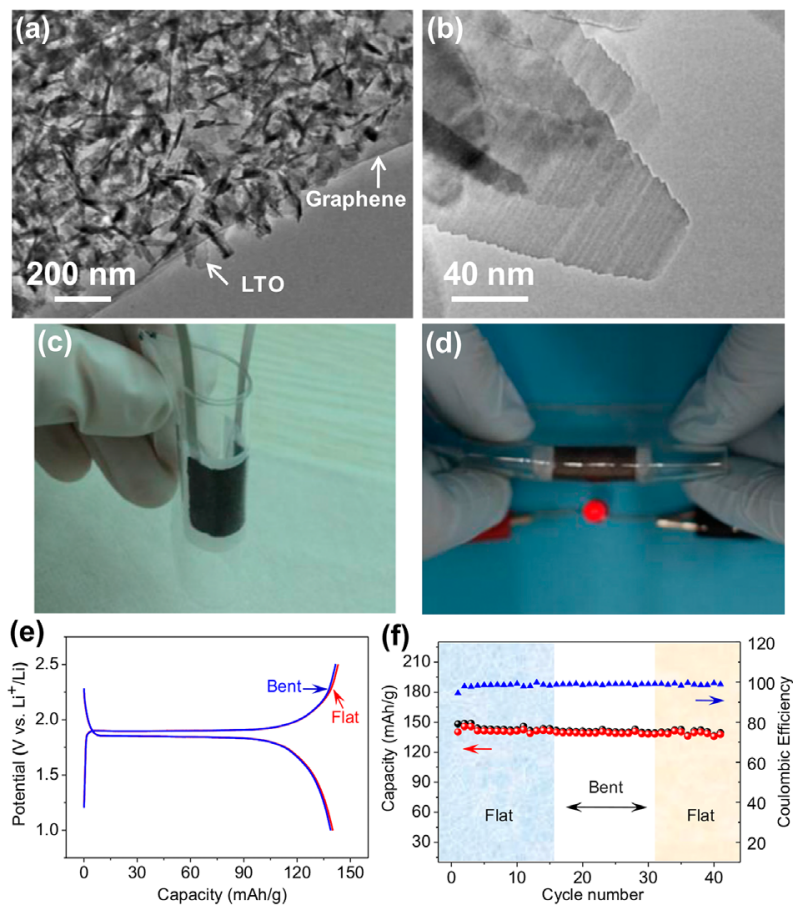

Figure 6. / by Guozhen Shen et al. 


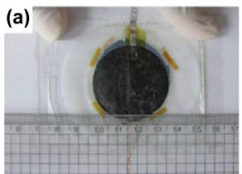

(c)

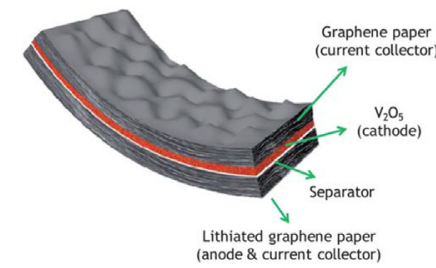

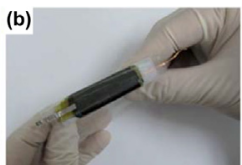

(anode \& current collector)
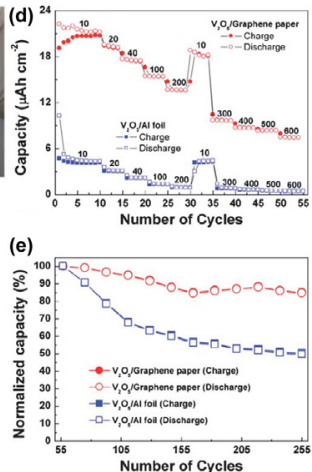

Figure 7. / by Guozhen Shen et al.

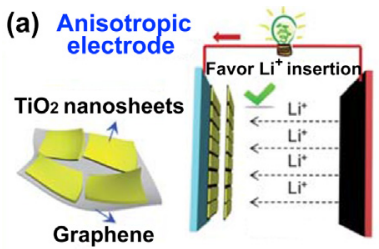

(b) Isotropic

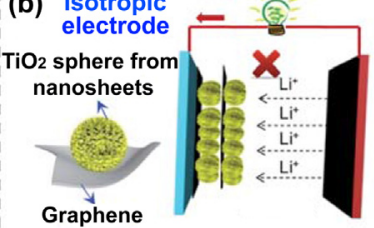

(c)

(d)
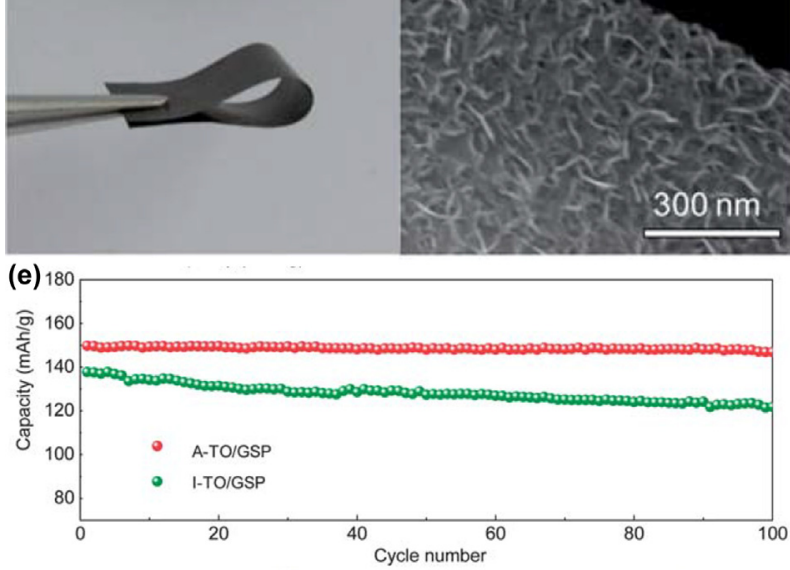

Figure 8. / by Guozhen Shen et al. 


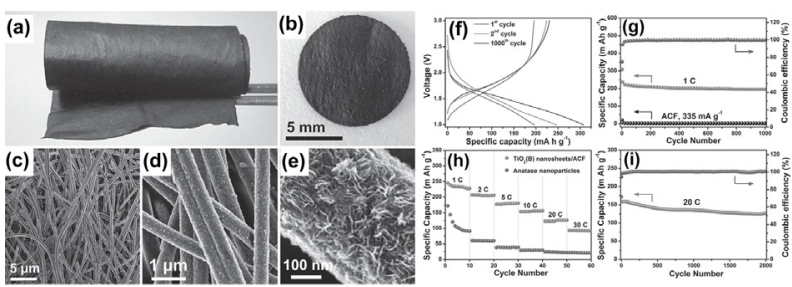

Figure 9. / by Guozhen Shen et al.

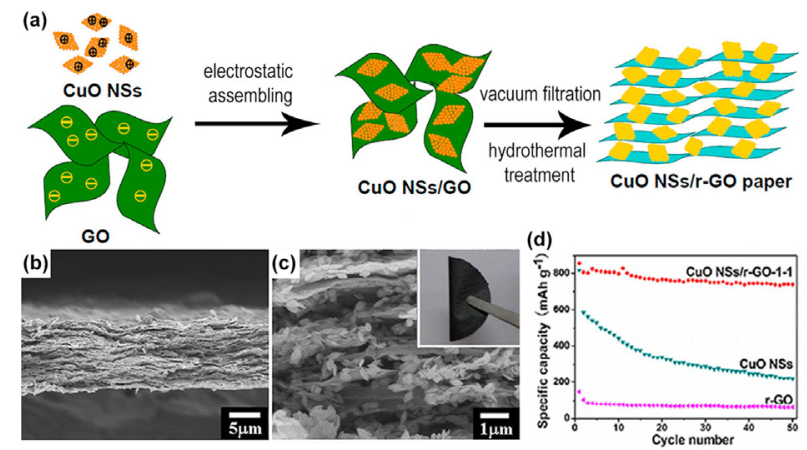

Figure 10. / by Guozhen Shen et al. 


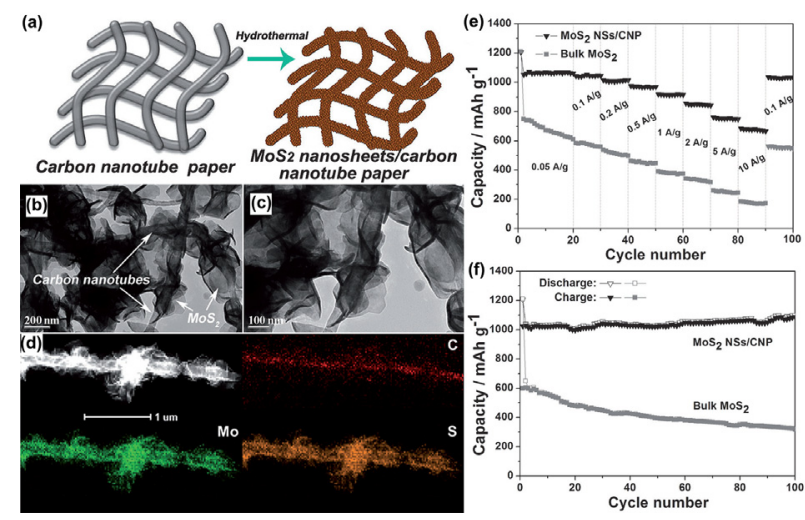

Figure 11. / by Guozhen Shen et al.

(a)
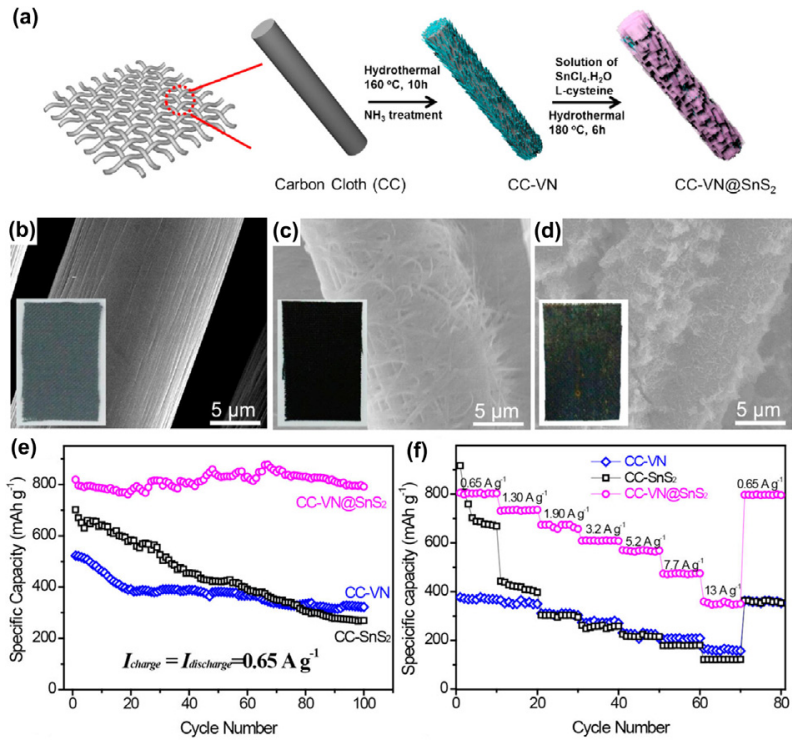

Figure 12. / by Guozhen Shen et al. 


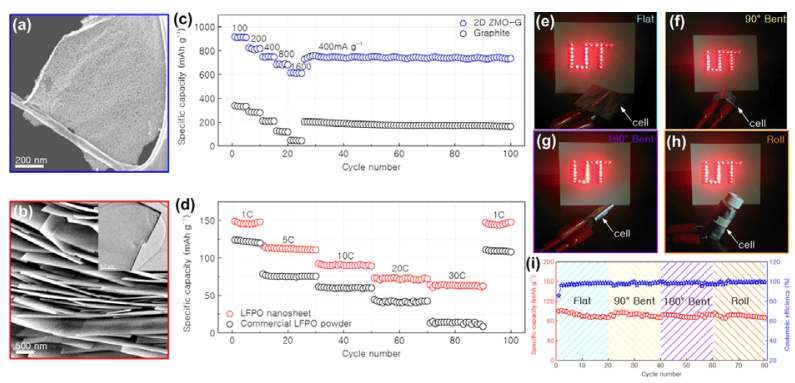

Figure 13. / by Guozhen Shen et al.

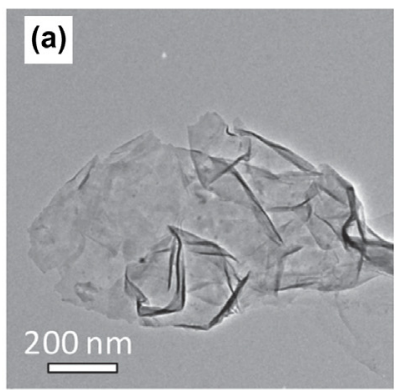

(b)

Carbon layer

(c)

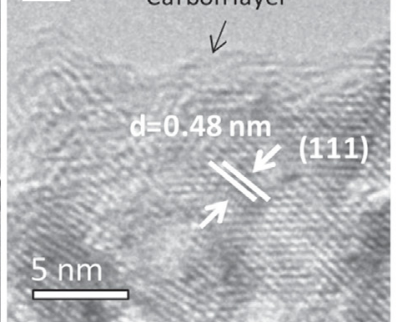

(d)

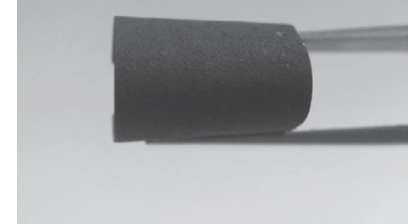

(d)

(e)

100C 50C 10C 5C 1C

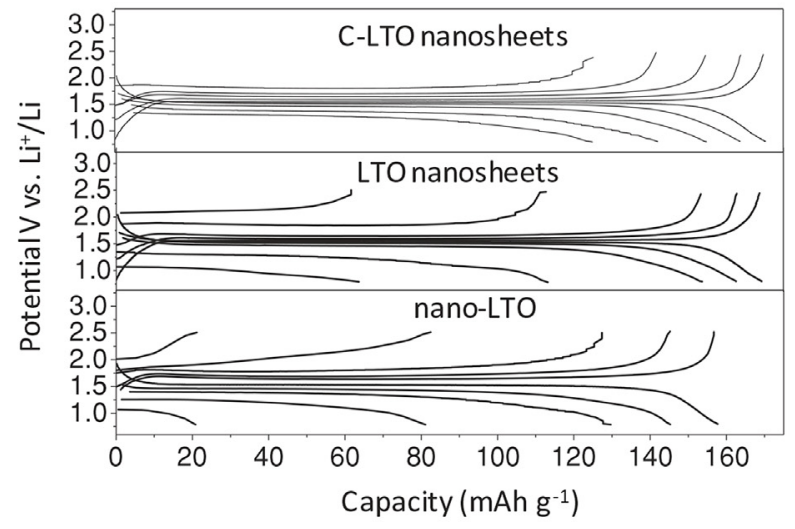

Figure 14. / by Guozhen Shen et al. 